\title{
In memoriam Hermann Hartmann, founder of TCA, on the occasion of his 100th birthday
}

\author{
W. H. Eugen Schwarz • Fritz Grein • \\ Klaus Ruedenberg
}

Published online: 2 July 2014

(c) Springer-Verlag Berlin Heidelberg 2014

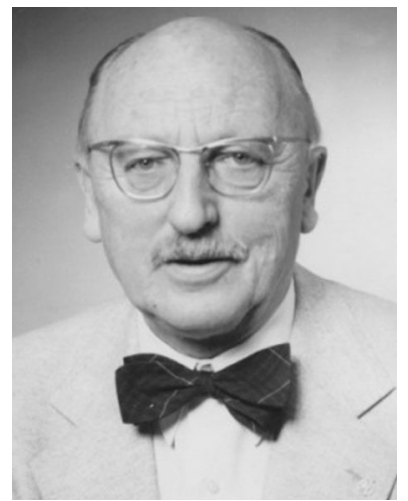

Hermann Hartmann was born on May 4, 1914, in Bischofsheim an der Rhön, about $130 \mathrm{~km}$ northeast of Frankfurt am Main. He received a classical education in a humanistic Gymnasium, where he excelled in ancient Greek and Latin. In 1933, he began studies in chemistry at

W. H. E. Schwarz ( $\square)$

Chemistry Department, Tsinghua University,

Beijing 100084, China

e-mail: Schwarz@chemie.uni-siegen.de

W. H. E. Schwarz

Chemistry Department, University of Siegen,

Siegen 57068, Germany

F. Grein

Chemistry Department, University of New Brunswick,

Fredericton E3B5A3, Canada

e-mail: Fritz@unb.ca

K. Ruedenberg

Chemistry Department and Ames Laboratory USDOE,

Iowa State University, Ames, IA 50011, USA

e-mail: Ruedenberg@iastate.edu the Institute of Technology and at the Ludwig Maximilian University in Munich. Among his teachers were the theoretical physicist Arnold Sommerfeld and the experimental isotope researcher Klaus Clusius. In 1939, he moved to the Johann Wolfgang Goethe University in Frankfurt to work on his thesis with the electrochemist Peter Wulff and, after being exempted from the draft because of illness, he completed his Ph.D. in 1941. He attained the Habilitatio in 1943, but he was appointed as "Privat-Dozent" and "Assistent" at the University of Frankfurt only in 1946. In 1951, he became a section leader at the Max Plank Institute for Physical Chemistry in Göttingen. In 1952, he returned to the University of Frankfurt as Director of the Institute for Physical Chemistry. He retired as Professor Emeritus in 1982 and died on October 22, 1984.

Upon coming to Frankfurt, Hartmann's goal was to build up the institute into a center for experimental and theoretical studies that would be in the vanguard of modern physical chemistry and chemical physics in its full depth and breadth. His teaching covered classical physical chemistry and spectroscopy as well as statistical mechanics and quantum mechanics. A broad range of experimental investigations of structures and kinetics of condensed phases as well as of molecules in the gas phase was pursued with a broad range of spectroscopic techniques: $\mathrm{X}$-ray, ultraviolet, visible, infrared, microwave, nuclear magnetic resonance, and ion-cyclotron resonance methods.

Theoretical chemistry was however the discipline on which Hartmann had set his heart since the time that he had published a paper with Arnold Sommerfeld on the quantum mechanical rotor in 1940. His habilitation thesis (1943) was on chemical bonding in the context of Hückel theory. After becoming Dozent (1946), he developed a number of semi-empirical schemes for the description of chemical bonds. He made a notable impact (together with his first 
student F. E. Ilse) by his generalization of crystal field theory to ligand field theory, the first work on this subject, and a major advance in the understanding of transition metal complexes. Theoretical chemistry remained Hartmann's favorite science after he became head of the institute in Frankfurt. He continued theoretical investigations on a variety of subjects and, in the $1960 \mathrm{~s}$, more than 20 of the 100 members of his institute worked on theoretical problems. In 1968, he created a Center for Theoretical Chemistry. While promoting the use of computers, he insisted on using one's own brain. Conceptual aspects remained paramount to him.

As a Nestor in German quantum chemistry, Hartmann, moreover, considered it a major task of his to revive this discipline in Germany, where it had been neglected. He wrote an excellent book (1954) on quantum chemistry, the first in German after Hellmann's book of 1937. He arranged a lecture series for chemists on the "chemical bond." He organized yearly summer schools (1962-1973), notably in Konstanz, which were focused on specific theoretical themes and had high-level lecturers such as Manfred Eigen, Rudolph Marcus and Gerhard Ertl. In 1965, he initiated the annual Symposium für Theoretische Chemie in the Germanspeaking regions, the 50th of which will take place this fall in Vienna. In 1962, he founded the first journal exclusively devoted to theoretical chemistry, Theoretica Chimica Acta, and edited it for 23 years.

Hermann Hartmann was a man of firm independent convictions-in life as well as in science. He was deeply committed to the values of the classical liberal European tradition that derived from the humanism of the Renaissance. Because he did not adapt his political views to those of the Nazi regime, he was not appointed Dozent at the University of Frankfurt until after the end of the war, when the regime had fallen. From a similar perspective, he showed little sympathy for the cultural revolts starting at German universities in the late 1960s. As a result, he was politically forced to give up nearly all his experimental work at the university in the mid-seventies and limit his activities mostly to theoretical chemistry and to a small research institute supported by the Mainzer Akademie der Wissenschaften. It is also a sign of his strongly independent personality that he decided to carry the torch for theoretical chemistry at a time when it was not fashionable in Germany.

By virtue of his humanistic philosophy, he chose not only the title but the entire front cover of Theoretica Chimica Acta to be in Latin and decreed English, French, German as well as Latin to be admissible publication languages. He himself published a paper in Latin. As the twentieth century progressed, he had to reconcile himself to English becoming the lingua franca of the sciences; more and more of the lectures at the Symposia für Theoretische Chemie were in English. From 1985 on, all articles in
Theoretica Chimica Acta were in English and, in 1997, TCA became Theoretical Chemistry Accounts.

On a personal level, Hartmann exhibited a warm personality. Even though he had a large group of coworkers, he found time to talk regularly to his graduate students. He showed his interest in their personal problems as well as in their scientific progress. He gave good advice and was helpful whenever possible.

Hermann Hartmann was honored by being elected a member by the Deutsche Akademie der Naturforscher Leopoldina, by the Academia Nazionale dei Lincei, by the Kongelige Danske Videnskabernes Selskab, by the Pakistan Academy of Sciences, by the International Academy of Quantum Molecular Sciences, by the Akademie der Wissenschaften und der Literatur Mainz, and as an honorary member by the Verein Österreichischer Chemiker.

A Festsymposium in memory of Hermann Hartmann was held at the University of Frankfurt on May 4, 2014. Fuller biographical accounts have recently been written by Anne Hardy ${ }^{1}$ and by Karl Jug. ${ }^{2}$ They are scheduled for publication later this year. The present authors thank Dr. Hardy and Professor Jug for making preprints of their articles available as sources of information, and Professors D. Schuch, H. W. Sillescu and H. Spiess for informative comments.

Editor's Note: Coauthors Fritz Grein and W. H. Eugen Schwarz received their $\mathrm{PhD}$ under the supervision of H. Hartmann in 1960 and 1969, respectively. Toward the end of 1983, coauthor Klaus Ruedenberg was approached by H. Hartmann about taking the helm of his Journal. Ruedenberg served as editor-in-chief of Theoretica Chimica Acta from 1985 to 1997.

\footnotetext{
1 Anne Hardy, Hermann Hartmann-Pionier der Theoretischen Chemie, in the journal Forschung Frankfurt, published by the Goethe-Universität Frankfurt am Main, issue 2014(2), which is to appear in print as a Festschrift for the centennial of this university in December 2014.

${ }^{2}$ Karl Jug, Zweihundert Jahre Entwicklung der Theoretischen Chemie im deutschsprachigen Raum, 1800-2000, Section 4.2, (Springer Verlag, Heidelberg, in press).
} 